\title{
ЗОНАЛЬНОСТЬ И УСЛОВИЯ ОБРАЗОВАНИЯ КОВДОРСКОЙ ФОСКОРИТ-КАРБОНАТИТОВОЙ ТРУБКИ
}

\author{
Иванюк Г.Ю. ${ }^{1,2}$, Калашников А.О. ${ }^{1}$ Михайлова Ю.А. ${ }^{1,2}$, Пахомовский Я.А. ${ }^{1,2}$, \\ Паникоровский Т.Л. ${ }^{2}$, Коноплёва Н.Г. ${ }^{2}$, Базай А.В. ${ }^{1,2}$, Горяинов П.М. ${ }^{1}$, Елизарова И.Р. ${ }^{2}$, \\ Сохарев В.А. ${ }^{3}$, Яковенчук В.Н. ${ }^{1,2}$ \\ ${ }^{1}$ Геологический институт КНЦ РАН; ${ }^{2}$ Центр наноматериаловедения КНЦ РАН \\ ${ }^{3} \mathrm{OОO} \mathrm{«Ковдорский} \mathrm{ГОК»}$
}

Ковдорский фоскорит-карбонатитовый комплекс, сформировавшийся на заключительном этапе становления одноименного массива перидотитов, фоидолитов-мелилитолитов и связанных с ними диопсидитов, флогопититов и скарноидов около 400 млн. лет тому назад, представляет собой концентрически-зональную трубку с грушевидным сечением $1.5 \times 0.7$ км (рис. 1), которая, постепенно сужаясь, уходит на глубину более 2 км [1]. Ее петрографическая зональность, установленная методом 3-мерного геологического картирования по всей совокупности буровых данных, накопленных с 1950 по 2015 г. [2], определяется постепенной сменой от края к осевой зоне (апатит)форстеритовых фоскоритов существенно магнетитовыми бескарбонатными фоскоритами и, затем, карбонатсодержащими фоскоритами и кальцитовыми карбонатитами фоскоритового ряда. По границе между осевой и промежуточной зонами развит кольцевой штокверк жильных кальцитовых карбонатитов, а через осевую зону трубки в СВ направлении проходит линейная зона развития даек доломитовых карбонатитов и связанных с ними магнетито-доломито-серпентиновых метасоматитов [1].

Детальное изучение закономерностей изменения содержания, гранулометрии, состава, условий кристаллизации и субсолидусного изменения большинства сквозных минералов в пределах фоскорит-карбонатитовой трубки позволило получить 3-мерную модель распределения этих характеристик в пределах фоскорит-карбонатитовой трубки при помощи программного комплекса MicroMine 2016 (см. рис. 1) и, на основании ее анализа, сделать следующие выводы [1-8]:

1. Геохимическая эволюция фоскорит-карбонатитового комплекса заключается в последовательном возрастании от краевых (апатит)-форстеритовых фоскоритов к осевым карбонатсодержащим фоскоритам и карбонатитам содержания $\mathrm{C}, \mathrm{S}, \mathrm{Ca}, \mathrm{Sr}, \mathrm{Ba}, R E E, \mathrm{U}, \mathrm{Th}, \mathrm{Nb}, \mathrm{Ta}, \mathrm{Cu}$ и $\mathrm{Pb}$ за счёт $\mathrm{Si}, \mathrm{Ti}, \mathrm{Al}, \mathrm{Mg}, \mathrm{Na}, \mathrm{K}, \mathrm{Rb}, \mathrm{Cr}$ и Ni, тогда как Fe, P, F, Zr, Hf, V, Sc, Zn, Со и Аg концентрируются в промежуточных существенно магнетитовых бескарбонатных фоскоритах;

2. В краевых (апатит)-форстеритовых фоскоритах получили распространение форстерит с повышенным содержанием $\mathrm{Fe}^{2+}$, магнетит с повышенным содержанием $\mathrm{Mn}$, Ti и $\mathrm{Si}$ и экссолюционными ламелями ильменита, гидроксилапатит, обогащенный $\mathrm{Fe}$ и $\mathrm{Mg}$, бадделеит с микропримесями $\mathrm{Mn}, \mathrm{Fe}$ и $\mathrm{Si}$, минералы группы пирохлора, обогащенные $\mathrm{Na}, \mathrm{Ca}, R E E$ и $\mathrm{Th}$, а также никелистый пирротин-4C с экссолюционными ламелями пентландита;

3. Промежуточные существенно магнетитовые фоскориты включают $\mathrm{Fe}^{3+}$-содержащий форстерит, обогащенный $\mathrm{Mg}$ и $\mathrm{Al}$ магнетит с экссолюционными включениями шпинели, беспримесные гидроксилапатит, бадделеит и пирохлор, а также $\mathrm{Ni}-\mathrm{Co}-$ содержащий пирротин- $4 C-5 C \mathrm{c}$ ламелями (кобальт)пентландита;

4. Осевые карбонатсодержащие фоскориты и карбонатиты включают форстерит, обогащенный

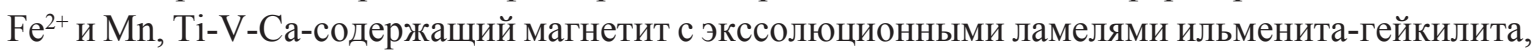
$\mathrm{Ba}-\mathrm{Sr}-R E E$-содержащий гидроксилапатит, бадделеит, обогащенный $\mathrm{Hf}, \mathrm{Ta}, \mathrm{Nb}$ и $\mathrm{Sc}$ до промышленно значимого уровня, минералы группы пирохлора, обогащенные $\mathrm{Ba}, \mathrm{Sr}, \mathrm{U}, \mathrm{Ta}, \mathrm{Fe}$ и $\mathrm{Zr}$, а также кобальтистый пирротин-5C с экссолюционными ламелями кобальтпентландита;

5. Пристеночная кристаллизация фоскоритовой магмы начинается с форстерита, что приводит к разрушению силикатно-карбонатно-феррифосфатной матрицы расплава и образованию апатита и магнетита, с локализацией остаточного карбонатитового расплава, обогащенного редкими металлами, в осевой части трубки; 

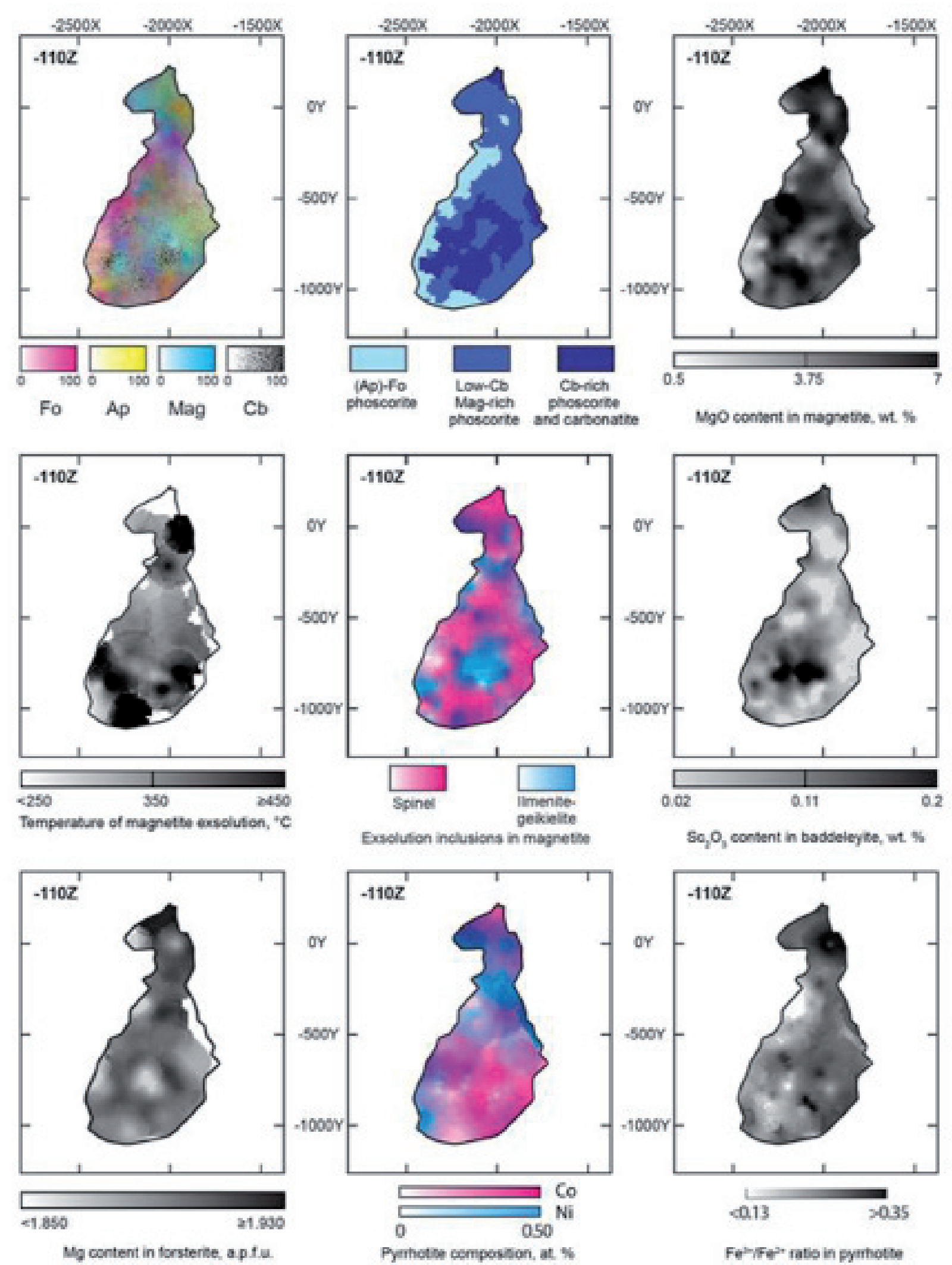

Рис. 1. Зональность Ковдорской фоскорит-карбонатитовой трубки на горизонте -110 м. 
6. Субсолидусная эволюция большинства сквозных минералов заключается в распаде твердых растворов, температура которого последовательно уменьшается от края фоскориткарбонатитовой трубки к ее осевой зоне от 500 до $400^{\circ} \mathrm{C}$ для пары кальцит-доломит, от 500 до $300^{\circ} \mathrm{C}$ для титаномагнетита и от 250 до $150^{\circ}$ для пары пирит-пирротин;

7. Линейное уменьшение отношения $\mathrm{Fe}^{3+} / \mathrm{Fe}^{2+}$ в пирротине в естественной последовательности ковдорских пород от вмещающих фоидолитов и диопсидитов к фоскоритам и, затем, карбонатитам с видетельствует о последовательном уменьшении фугитивности кислорода в этом направлении, связанном с последовательным же уменьшением щелочности пород. По данным магнетит-ильменитового геооксометра фугитивность кислорода уменьшается в рассматриваемом ряду от $\mathrm{NNO}+1$ до $\mathrm{NNO}-2$;

8. При переработке первичных минералов фоскорит-карбонатитового комплекса поздними гидротермальными растворами, обогащенными фтором, образуются редкие минералы и политипы, в частности гидроксинатропирохлор, кампелит, пахомовскит, кваинтинит- $1 M,-3 R,-2 H-3 c$, пирротин-5C (C2) и др., температура кристаллизации которых не превышает $100{ }^{\circ} \mathrm{C}$, а структурная сложность существенно превышает таковую более высокотемпературных аналогов;

9. Полученные результаты и разработанные подходы к их интерпретации позволяют перейти
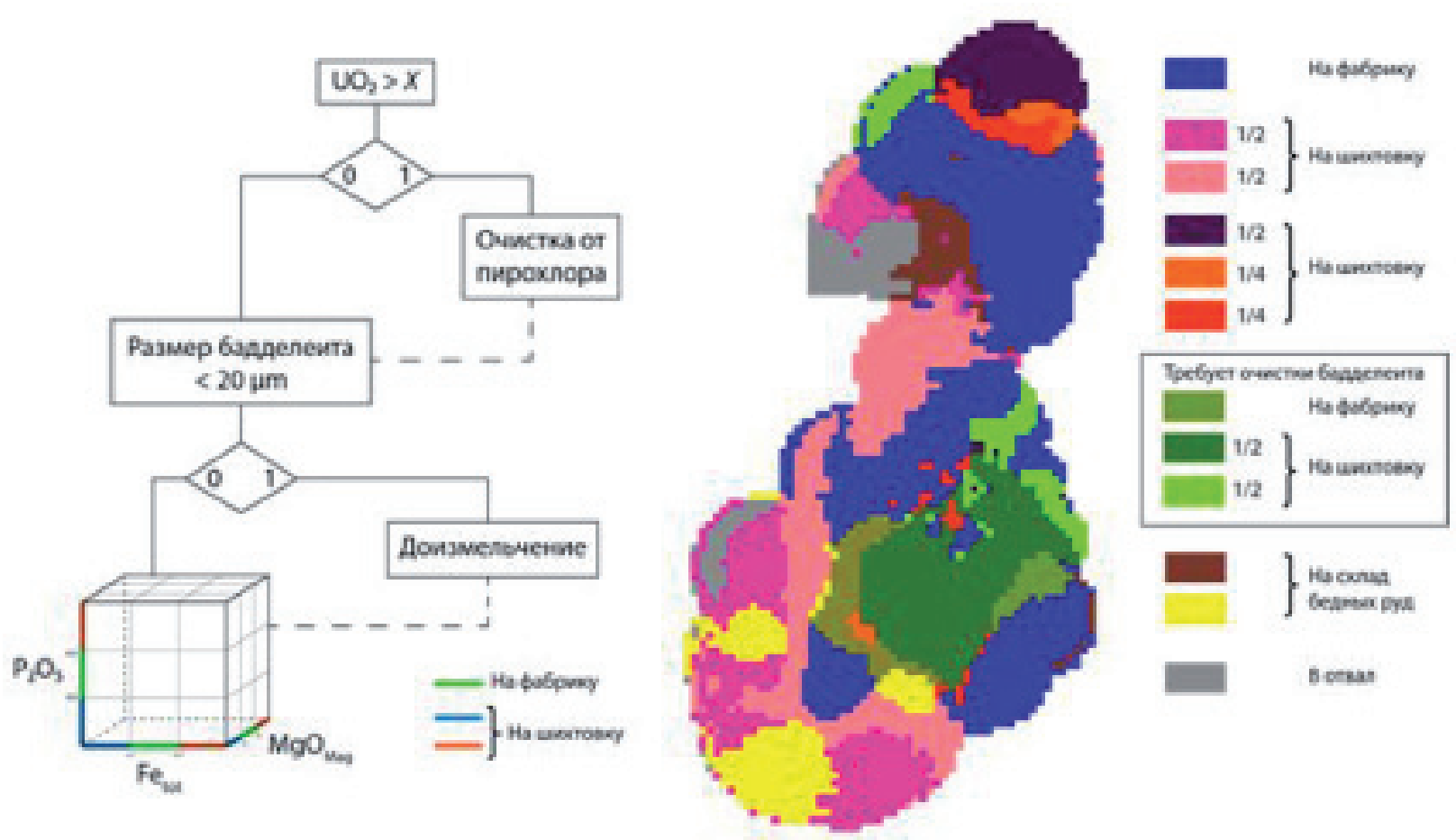

Рис. 2. Принципиальная схема построения геометаллургической модели Ковдорского месторождения

к геометаллургическому моделированию Ковдорского месторождения магнетита, апатита и бадделеита (рис. 2) с целью оптимизации добычи и обогащения комплексных руд.

Работа выполнена в рамках проекта РНФ 16-17-10173.

\section{Литература}

1. Mikhailova, J.A., Kalashnikov, A.O., Sokharev, V.A., Pakhomovsky, Ya.A., Konopleva, N.G., Yakovenchuk, V.N., Bazai, A.V., Goryainov, P.M., Ivanyuk, G.Yu. 3D mineralogical mapping of the Kovdor phoscorite-carbonatite complex (Russia) // Mineralium Deposita. 2016. V. 51 (1). P. 131-149.

2. Kalashnikov A.O., Ivanyuk G.Yu., Mikhailova J.A., Sokharev V.A. Approach of automatic 3D geological mapping: the case of the Kovdor phoscorite-carbonatite complex, NW Russia. Scientific Reports. 2017. 7:6893. Doi: 10.1038/s41598-017-06972-9 
3. Ivanyuk G.Yu., Kalashnikov A.O., Pakhomovsky Ya.A., Mikhailova J.A., Yakovenchuk V.N., Konopleva N.G., Sokharev V.A., Bazai A.V., Goryainov P.M. Economic minerals of the Kovdor baddeleyite-apatitemagnetite deposit, Russia: mineralogy, spatial distribution, and ore processing optimization // Ore Geology Reviews. 2016. V. 77. P. 279-311.

4. Ivanyuk G.Yu., Kalashnikov A.O., Pakhomovsky Ya.A., Bazai A.V., Goryainov P.M. Mikhailova J.A., Yakovenchuk V.N. Konopleva N.G. Subsolidus evolution of the magnetite-spinel-ulvöspinel solid solutions in the Kovdor phoscorite-carbonatite complex, NW Russia // Minerals. 2017. 7, 215. DOI:10.3390/min7110215.

5. Kalashnikov A.O., Yakovenchuk V.N., Pakhomovsky Ya.A., Bazai A.V., Sokharev V.A., Konopleva N.G., Mikhailova J.A., Goryainov P.M., Ivanyuk G.Yu. Scandium of the Kovdor baddeleyite-apatite-magnetite deposit (Murmansk Region, Russia): Mineralogy, spatial distribution, and potential resource // Ore Geology Reviews. 2016. V. 72. P. 532-537.

6. Yakovenchuk V.N., Ivanyuk G.Yu., Pakhomovsky Ya.A., Panikorovskii T.L., Britvin S.N., Krivovichev S.V., Shilovskikh V.V., Bocharov V.N. Kampelite, $\mathrm{Ba}_{3} \mathrm{Mg}_{1.5} \mathrm{Sc}_{4}\left(\mathrm{PO}_{4}\right)_{6}(\mathrm{OH})_{3} \cdot 4 \mathrm{H}_{2} \mathrm{O}$, a new very complex Ba-Sc phosphate mineral from the Kovdor phoscorite-carbonatite complex (Kola Peninsula, Russia) // Mineralogy and Petrology. 2017. V. 112. P. 111-121. DOI 10.1007/s00710-017-0515-1.

7. Zhitova E.S., Krivovichev S.V., Yakovenchuk V.N., Ivanyuk G.Yu., Pakhomovsky Ya.A., Mikhailova J.A. Crystal chemistry of natural layered double hydroxides. 4. Crystal structures and evolution of structural complexity of quintinite polytypes from the Kovdor alkaline massif, Kola peninsula, Russia // Mineralogical Magazine. 2017. DOI: 10.1180/minmag.2017.081.046.

8. Ivanyuk G.Yu., Yakovenchuk V.N., Panikorovskii T.L., Konoplyova N.G., Pakhomovsky Ya.A., Bazai A.V., Bocharov V.N., Krivovichev S.V. Hydroxynatropyrochlore, (Na,Ca,Ce) ${ }_{2} \mathrm{Nb}_{2} \mathrm{O}_{6}(\mathrm{OH})$, a new member of the pyrochlore group from the Kovdor phoscorite-carbonatite pipe (Kola Peninsula, Russia) // Mineralogical Magazine. 2018. DOI: 10.1180/minmag.2017.081.102. 